\title{
Correction to: Scaling up SDGs Implementation: Emerging Cases from State, Development and Private Sectors
}

Godwell Nhamo, Gbadebo O. A. Odularu, and Vuyo Mjimba

\section{Correction to:}

G. Nhamo et al. (eds.), Scaling up SDGs Implementation, Sustainable Development Goals Series, https://doi.org/10.1007/978-3-030-33216-7

The original version of the Chapters 6 and 7 were inadvertently published with the corresponding author's name as "Dube Kaitano". The author's name has now been corrected to "Kaitano Dube".

The updated online version of these chapters can be found at https://doi.org/10.1007/978-3-030-33216-7_6 https://doi.org/10.1007/978-3-030-33216-7_7 https://doi.org/10.1007/978-3-030-33216-7 